\title{
LA MODIFICACIÓN DEL TEXTO REFUNDIDO DE LA LEY DE EVALUACIÓN DE IMPACTO AMBIENTAL DE PROYECTOS POR LA LEY 6/2010, DE 24 DE MARZO
}

\author{
JosÉ ANTONIO RAZQUIN LIZARRAGA \\ Profesor doctor asociado \\ Universidad de Navarra \\ jrazquinl@gmail.com
}

Recibido: 3 de mayo de 2010 / Aceptado: 24 de mayo de 2010

RESUMEN: La Ley 6/2010 modifica el Texto Refundido de la Ley de evaluación de impacto ambiental de proyectos (TRLEIAP) para incorporar las técnicas de la declaración responsable y la comunicación, así como fijar plazos a fin de agilizar la realización de la EIA. La reforma afecta primordialmente a la Administración General del Estado, pero también se incorporan varias modificaciones de carácter básico.

RESUM: La Llei 6/2010 modifica el Text Refós de la Llei d'avaluació d'impacte ambiental de projectes per incorporar les tècniques de la declaració responsable i la comunicació, així com fixar terminis a fi i a efecte d'agilitzar la realització de l'AIA. La reforma afecta, primordialment, a l'Administració General de l'Estat, però també s'introdueixen modificacions de caràcter bàsic.

ABSTRACT: The consolidated text (2008) of the Environmental Impact Assessment Act, where is regulated this subject at national level, has been amended by Environmental Impact Assessment Amendment Act 2010, which introduces the responsible statement and notification, and settles periods to fulfil the different actuations within the procedure, in order to speed up the EIA. The amendment affects mainly to central government, but in some aspects to regional governments as well. 
PALABRAS CLAVE: Evaluación de impacto ambiental — òrgano sustantivo declaración responsable — comunicación — plazos

PARAULES CLAU: Avaluació d'impacte ambiental — òrgan substantiu — declaració responsable — comunicació — terminis

KEYWORDS: Environmental impact assessment - substantive authority responsible declaration — notification — periods

Sumario: I. Objetivos de la Ley 6/2010 y modificaciones dispares del TRLEIAP. II. Título competencial: legislación básica y preceptos no básicos del TRLEIAP tras la Ley 6/2010. III. Modificaciones derivadas de la transposición de la Directiva de servicios. 1. El cambio de paradigma en la Directiva de servicios: de la intervención preventiva al control posterior. 2. La nueva definición de órgano sustantivo. 3. La incorporación de las técnicas de la declaración responsable y la comunicación. IV. Otras modificaciones de carácter básico. V. Modificaciones referidas a la Administración General del Estado. 1. Medidas para la eficacia y agilidad: plazos. 2. Reformas de incorporación formal de las técnicas de control posterior. 3. La evaluación de proyectos estatales que puedan afectar de forma apreciable a espacios de la Red Natura 2000. VI. Conclusión. VII. Bibliografía.

\section{OBJETIVOS DE LA LEY 6/2010 Y MODIFICACIONES DISPARES DEL TRLEIAP}

La Ley 6/2010, de 24 de marzo, modifica quince preceptos del Texto Refundido de la Ley de Evaluación de Impacto Ambiental de proyectos (TRLEIAP) aprobado por Real Decreto Legislativo 1/2008, de 11 de enero. Tiene vigencia inmediata (26 de marzo de 2010), pero no se aplica a los procedimientos de EIA iniciados con anterioridad a su entrada en vigor, esto es, cuando la solicitud de iniciación, acompañada del documento inicial, ha recibido la conformidad del órgano sustantivo de acuerdo con el art. 6.2 del TRLEIAP (disposiciones final y transitoria primera Ley 6/2010). Su finalidad no es la incorporación de la última reforma de la Directiva 85/337/CEE (Directiva EIA) ${ }^{1}$, sino obedece a otra justificación.

\footnotetext{
1 Directiva 2009/31/CE del Parlamento Europeo y del Consejo de 23 de abril de 2009 relativa al almacenamiento geológico de dióxido de carbono y por la que se modifican la Directiva 85/337/CEE del Consejo, las Directivas 2000/60/CE, 2001/80/CE, 2004/35/CE, 2006/12/CE, 2008/1/CE y el Reglamento (CE) no 1013/2006 del Parlamento Europeo y del Consejo. La modificación de la Directiva EIA se refiere al Anexo I con el fin de incluir en su ámbito de aplicación la captura y el transporte de los flujos de CO2 con fines de almacenamiento geológico, así como los emplazamientos de almacenamiento (considerando $45 \mathrm{y}$ art. 31).
} 
La reforma del TRLEIAP, según la exposición de motivos de la Ley 6/2010, tiene dos objetivos: 1) La adaptación de la evaluación de impacto ambiental (EIA) dentro de un marco temporal preciso y determinado, para lograr una mayor eficacia en su realización, basada en la claridad del procedimiento y en la corresponsabilidad de todos los agentes intervinientes en el mismo, con trámites administrativos más ágiles, de modo que la EIA sea un instrumento facilitador de la actividad económica y social; y 2) La adecuación de la normativa de impacto ambiental al nuevo paradigma derivado de la Directiva de servicios y su transposición estatal, consistente en la preferencia de la intervención administrativa posterior o represiva sobre la previa o preventiva, con la supresión de un gran número de autorizaciones administrativas que son sustituidas por una declaración responsable o comunicación del prestador, a partir de la específica previsión de la disposición adicional quinta de la Ley 25/2009.

No obstante, las reformas introducidas por la Ley 6/2010 van más allá de esos objetivos y son mayores que las inicialmente previstas. El proyecto de Ley remitido por el Gobierno a las Cortes Generales ${ }^{2}$ fue alterado durante su tramitación parlamentaria, que incorporó las modificaciones (mayoritariamente de carácter básico y aplicación general) siguientes: párrafo segundo del art. $2.2^{3}$; art. 5.3 ${ }^{4}$; art. $6.3^{5}$; inciso final del párrafo primero del art. $12.2^{6}$; inciso final del párrafo tercero del art. $12.3^{7}$; nueva redacción del art. 16.1 con un nuevo párrafo final ${ }^{8}$; inciso final en el párrafo primero del art. 18 bis. $1^{9}$; y nuevo párrafo en la disposición adicional primera ${ }^{10}$.

\footnotetext{
${ }^{2}$ Boletín Oficial de las Cortes Generales, Congreso de los Diputados, Serie A, Núm. 33-1, de 31 de julio de 2009.

${ }^{3}$ Aceptando en parte la enmienda núm. 9 del Grupo Parlamentario Popular en el Senado.

${ }^{4}$ Fruto de la enmienda núm. 16 del Grupo Parlamentario Popular en el Congreso de los Diputados.

${ }^{5}$ Enmienda núm. 2 del Grupo Parlamentario Popular en el Congreso de los Diputados.

${ }^{6}$ Enmienda núm. 18 del Grupo Parlamentario de Esquerra Republicana-Izquierda Unidad-Iniciativa per Catalunya Verds en el Congreso de los Diputados.

${ }^{7}$ Enmienda núm. 6 del Grupo Parlamentario Popular en el Congreso de los Diputados.

8 Enmiendas núm. 9 del Grupo Parlamentario Popular y núm. 25 del Grupo Parlamentario Catalán (Convergencia i Unió) en el Congreso de los Diputados.

${ }^{9}$ Enmienda núm. 11 de la Sra. Fernández Dávila (Grupo Parlamentario Mixto) en el Congreso de los Diputados.

${ }^{10}$ Enmienda núm. 26 del Grupo Parlamentario Popular en el Congreso de los Diputados, con nueva redacción en el Senado que pasará al texto legal. En el Senado, la enmienda núm. 13 del Grupo Parlamentario Socialista propuso su modificación justificada en el cumplimiento del Derecho comunitario. Una modificación similar de la disposición adicional primera -que añade los centros penitenciarios a los proyectos relacionados con los objetivos de la Defensa Nacional- ya aparecía en el
} 
Por tanto, la Ley 6/2010 lleva a cabo modificaciones dispares del TRLEIP, que pueden ordenarse para su análisis bajo distintos criterios. Aquí, por razones de sistemática y alcance, se van a examinar sucesivamente el título competencial (II), las reformas generales que obedecen a la finalidad expresada en su exposición de motivos de acoger el cambio derivado de la transposición de la Directiva de servicios (III), los otros cambios de aplicación general (IV) y las modificaciones referidas exclusivamente a la Administración del Estado (V), con una valoración final (VI).

\section{TÍTULO COMPETENCIAL: LEGISLACIÓN BÁSICA Y PRECEPTOS NO BÁSICOS DEL TRLEIAP TRAS LA LEY 6/2010}

La Ley 6/2010 modifica el apartado 2 de la disposición final primera del TRLEIAP que establece aquellos preceptos que carecen del carácter de legislación básica en materia de medio ambiente y son, por ello, de aplicación únicamente a la Administración General del Estado y a sus organismos públicos (art. único.13); incidiendo, por ello, en su condición de legislación básica declarada en el apartado 1 .

El proyecto de Ley alteraba mínimamente la legislación básica, pues afectaba únicamente a la evaluación de impacto ambiental en el ámbito de la Administración General del Estado mediante preceptos de carácter no básico, salvo el nuevo art. 18 bis y sin perjuicio de modificar otros preceptos (arts. 2.2, 5.1 y 9.1 y 2 -si bien sus cambios sólo afectan al Estado- del TRLEIAP) que ya eran básicos y se mantenían con esa calificación.

Ese reajuste de preceptos incorporando los nuevos -con la salvedad del art. 18 bis- a la relación de preceptos no básicos, se ve alterado en el texto legal resultante. La reforma, aunque dirigida primordialmente al ámbito estatal, ha terminado por afectar también a las Comunidades Autónomas, pues se modifican o añaden además otros seis preceptos básicos (arts. 2.2 párrafo segundo, 5.3, 6.3, 12.2 párrafo primero, 16.1 párrafo último y nuevo párrafo en la disposición adicional primera) no previstos inicialmente.

No obstante, es reseñable la limitación de las reformas de las letras a) y c) del art. 9.2 del TRLEIP al ámbito estatal, en cuanto derivan de la incorporación de las formas de intervención posterior -declaración responsable y comunicación- respecto de todas las

anteproyecto según resulta del dictamen del Consejo de Estado de 25 de junio de 2009 (exp. 981/2009), pero no se incluyó en el proyecto remitido a las Cortes. 
Administraciones públicas en dos preceptos básicos (arts. 2.2 y 18 bis); y tal información, por identidad de razón con la referida a la autorización, es también obligada para las Comunidades Autónomas, pues se produce la paradoja de que éstas deben informar de la solicitud de autorización y de la identificación del órgano competente para resolver el procedimiento, sin que nada se diga respecto de los supuestos en que la técnica autorizatoria haya sido sustituida por tales medios de control posterior.

\section{MODIFICACIONES DERIVADAS DE LA TRANSPOSICIÓN DE LA DIRECTIVA DE SERVICIOS.}

\section{El cambio de paradigma en la Directiva de servicios: de la intervención preventiva al control posterior}

La Directiva de servicios y su transposición horizontal por la Ley 17/2009, de 23 de noviembre, sobre el libre acceso a las actividades de servicios y su ejercicio (llamada "Ley paraguas"), fijan el principio general según el cual el acceso a una actividad de servicios y su ejercicio no estarán sujetos a un régimen de autorización. Ello supone un cambio de paradigma: se pasa del sistema tradicional de intervención previa autorizaciones administrativas- a un control a posteriori. Esta preferencia por un control posterior lleva a categorizar nuevos medios de intervención represiva -la declaración responsable y la comunicación- que sustituyen a la autorización que pasa a ser excepcional, pues la norma legal que la prevea debe superar el triple test de no discriminación, necesidad justificada en una razón imperiosa de interés general y proporcionalidad (arts. 5 Ley 17/2009). Por su parte, la Ley 25/2009, de 22 de diciembre, de modificación de diversas leyes para su adaptación a la Ley sobre el libre acceso a las actividades de servicios y su ejercicio (denominada "Ley ómnibus"), establece medidas horizontales en materia de procedimiento administrativo incorporando las formas de intervención de la declaración responsable y la comunicación a las leyes de régimen local (nueva redacción del art. 84 Ley 7/1985, de 2 de abril, de bases de régimen local) y de procedimiento administrativo común (nuevos 
arts. 39 bis y 71 bis, así como nueva redacción del art. 43, de la Ley 30/1992, de 26 de noviembre) ${ }^{11}$.

El cambio de paradigma en la intervención administrativa podía afectar a la normativa de EIA, que gira en torno a la autorización, pues la EIA se ha de incorporar en el procedimiento de autorización o aprobación del proyecto (arts 1 y 2 de la Directiva 85/337/CEE y 1.2 TRLEIAP) ${ }^{12}$. El Consejo de Estado (dictamen de 21 de mayo de 2009, exp. 779/2009, sobre el anteproyecto de Ley ómnibus) propuso una nueva disposición adicional que ofrecía distintas alternativas como el considerar que cuando la legislación exige declaración de impacto debe interpretarse que la actividad o proyecto queda automáticamente sujeto a autorización a los efectos de la liberalización de servicios o que la propia legislación reguladora de la evaluación de impacto o de riesgos se modificara para establecer un procedimiento especial para emitir declaración de impacto ambiental, de sostenibilidad, de riesgos o equivalente con carácter previo a la comunicación o declaración responsable.

La Ley 25/2009 optó por la segunda de tales sugerencias, estableciendo que, cuando se exija una declaración responsable o una comunicación para el acceso a una actividad o su ejercicio y una EIA, aquéllas no podrán presentarse hasta haber realizado la EIA, debiendo disponerse de la documentación que así lo acredite (disposición adicional quinta). Ello incide en la normativa de EIA, que solo contempla la intervención previa mediante autorización o aprobación administrativas del proyecto. Por tanto, la Ley 6/2010 opera la adaptación del TRLEIAP con una nueva redacción del art. 2.2 (art. único.1) y el nuevo art. 18 bis (art. único.10), así como reformando determinados preceptos respecto de la Administración General del Estado.

\footnotetext{
${ }^{11}$ El nuevo art. 71 bis de la Ley 30/1992 regula con carácter general tales formas -ya previstas en algunas normas sectoriales- de la intervención represiva o posterior, fijando reglas de su régimen jurídico si bien con remisión a la legislación sectorial que las incorpore o establezca. Existe al respecto una amplia bibliografía. Por todos, me remito a RAZQUIN LIZARRAGA, J. A., "De la intervención administrativa previa al control a posteriori: la reforma del procedimiento administrativo común a consecuencia de la directiva de servicios", Revista Aranzadi Doctrinal núm. 2/2010 (BIB 2010\285).

12 RAZQUIN LIZARRAGA, J. A., La evaluación de impacto ambiental, Aranzadi, Elcano (Navarra), 2000, pp. 130-133 y 160-161; ROSA MORENO, J., "El ámbito de aplicación: los proyectos de obras, instalaciones y actividades sometidos a evaluación de impacto ambiental", Quintana López, T., Comentario a la legislación de evaluación de impacto ambiental, Civitas, Madrid, 2002, pp. 115-116; y GARCÍA URETA, A. "La evaluación de impacto ambiental (EIA), Lasagabaster Herrarte, I., García Ureta, A., Lazcano Brotons, I., Derecho Ambiental. Parte general, Lete y IVAP, Pamplona, 2004², p. 215. Por todas, la Sentencia del TJCE de 7 de enero de 2004 (C-201/02, Delena Wells).
} 


\section{La nueva definición de órgano sustantivo}

La primera de tales reformas se refiere a la definición de "órgano sustantivo" (art. 2.2 TRLEIAP), entendiéndose por tal "aquel órgano de la Administración pública estatal, autonómica o local competente para autorizar, para aprobar o, en su caso, para controlar la actividad a través de la declaración responsable o comunicación de los proyectos que deban someterse a evaluación de impacto ambiental" (párrafo primero). La modificación consiste, por tanto, en añadir a las técnicas de intervención preventiva, los nuevos medios de control a posteriori, determinando, en línea con la referencia a la autoridad competente en el art. 3.12 de la Ley 17/2009, que no es quien recibe la declaración responsable o comunicación, sino quien tiene la competencia material para su control ${ }^{13}$.

Ese criterio se perfila para el caso de concurrencia de varios controles - preventivos o represivos- respecto de la actividad a otorgar o ejercer por distintos órganos de la Administración Pública estatal, autonómica o local, considerándose órgano sustantivo aquel que ostente las competencias sobre la actividad a cuya finalidad se orienta el proyecto, con prioridad sobre los órganos que ostentan competencias sobre actividades instrumentales o complementarias respecto a aquellas (art. 2.2, párrafo segundo, añadido en sede parlamentaria). Se trata de una regla general de prevalencia, cuya aplicación puede ser en algunos casos problemática, primando la competencia resultante de la normativa sectorial o específica de la actividad a desarrollar.

Así pues, se mantiene el esquema precedente, con la consiguiente trascendencia de la determinación del órgano sustantivo pues atrae hacia esa Administración el órgano ambiental. En cambio, no prosperaron las enmiendas parlamentarias que pretendían bien considerar como órgano ambiental al autonómico en el caso de pluralidad de autorizaciones o aprobaciones y ubicación de proyectos en el ámbito de una comunidad autónoma $^{14} \mathrm{o}$ bien atribuir a la Comunidad Autónoma con competencias ejecutivas en esta materia la tramitación y resolución de las evaluación ambiental de los proyectos de

\footnotetext{
${ }^{13}$ Como señaló el Consejo de Estado en su dictamen de 25 de junio de 2009 (exp. 981/2009) sobre el anteproyecto de ley de modificación del TRLEIAP, cuya sugerencia se acoge en el articulado, pero sin trasladarla a la exposición de motivos.

${ }^{14}$ Enmiendas núm. 20 del Grupo Parlamentario de Esquerra Republicana-Izquierda Unidad-Iniciativa per Catalunya Verds en el Congreso de los Diputados y núm. 12 del Grupo Parlamentario Entesa Catalana de Progrés (GPECP) en el Senado.
} 
la competencia sustantiva estatal ${ }^{15}$, tratando de superar la doctrina de la STC 13/1998, de 22 de enero, sobre la accesoriedad de lo ambiental respecto de lo sustantivo en la EIA $^{16}$.

\section{La incorporación de las técnicas de la declaración responsable y la comunicación}

Un aspecto crucial consiste en asegurar la cabal aplicación de la normativa de EIA cuando se utilicen tales medios de control posterior, tanto el inexcusable carácter previo de la EIA, como el cumplimiento de las condiciones fijadas en la declaración de impacto ambiental. La Ley 25/2009 establece una exigencia específica y aporta una solución general: de un lado, el promotor debe realizar la EIA y acreditar su realización en la presentación de la declaración responsable y de la comunicación (disposición adicional quinta); y, de otro, tales técnicas devienen ineficaces en el caso de inexactitud, falsedad u omisión, de carácter esencial, en cualquier dato, manifestación o documentado acompañado a ellas (art. 71 bis, apartado 4, de la Ley 30/1992). Sin embargo, razones de claridad han motivado la regulación de esta cuestión en el TRLEIAP con la incorporación de un nuevo artículo ${ }^{17}$.

El nuevo art. 18 bis contiene dos previsiones: en primer lugar, la declaración responsable o la comunicación no podrá presentarse hasta haberse llevado a cabo la EIA, debiendo disponerse, en todo caso, de la documentación que así lo acredite y también de la publicación en el diario o boletín oficial correspondiente de la pertinente resolución (párrafo primero). Así pues, se preserva el carácter previo de la EIA que ha

\footnotetext{
15 Enmiendas núm. 27 del Grupo Parlamentario Catalán (Convergencia i Unió) en el Congreso de los Diputados y núm. 10 del Grupo Parlamentario Catalán en el Senado de Convergencia i Unió (GRCIU).

${ }^{16}$ RAZQUIN LIZARRAGA, J. A., La evaluación de impacto ambiental cit., pp. 199-202 y la bibliografía allí citada; QUINTANA LÓPEZ, T., "La evaluación de impacto ambiental", Quintana López, T., Comentario... cit., pp. 85-91; y LÓPEZ RAMÓN, F., "Evaluación de impacto ambiental de proyectos del Estado", RAP, núm. 160, 2003, pp. 11-48.

17 A decir del Consejo de Estado en su dictamen de 25 de junio de 2009 (exp. 981/2009) sobre el anteproyecto de ley de modificación del TRLEIAP: "Con independencia de ello, no queda claro en el proyecto cuáles son los efectos de la declaración de impacto ambiental sobre la comunicación o declaración responsable previa que, sin embargo, habiéndose sometido al procedimiento de evaluación de impacto, no se ajusta a lo exigido en la declaración de impacto. Aunque de la Ley de modificación de las diversas leyes que afectan a la libertad de acceso o prestación de servicios o de la Ley misma de regulación de dichas libertades parece derivarse que tal comunicación o declaración responsable no sería válida, sin embargo, debería añadirse algún precepto en el propio real decreto legislativo, por ejemplo en frase o apartado adicional al artículo 2.2 (o en un segundo artículo añadido al único del anteproyecto de Ley) que declarase tanto la invalidez como la ineficacia totales de la comunicación o declaración responsable que no se ajusten, bien ellas mismas bien los proyectos sobre los que se pronuncian, a lo determinado en la declaración de impacto ambiental."
} 
de preceder obligatoriamente a la presentación de la declaración responsable o la comunicación -como ya señala la disposición adicional quinta de la Ley 25/2009-, exigiendo su acreditación en la documentación correspondiente, así como la incorporación de la publicación de la declaración de impacto ambiental. La referencia final al término "resolución" -así como su interpretación sistemática con el párrafo segundo- cubre tanto la declaración de impacto ambiental, como también, en su caso, la resolución de no sometimiento a EIA.

Y, en segundo lugar, la declaración responsable o comunicación referida a un proyecto que no se ajuste a lo determinado en la declaración de impacto ambiental o en la resolución de no sometimiento a EIA carecerá de validez y eficacia a todos los efectos (art. 18 bis, párrafo segundo). Esta fórmula, distinta y más fuerte que la sanción general para el incumplimiento del art. 71 bis. 4 de la Ley 30/1992, lo es, como señala este último precepto, sin perjuicio de otras responsabilidades. Por tanto, es también de aplicación el régimen del control de cumplimiento de la legislación de EIA (arts. 18 a 23 del TRLEIAP), de suerte que el inicio de la actividad o proyecto por omisión o defectos de la EIA dará lugar a la suspensión de su ejecución así como a las sanciones administrativas correspondientes.

Por otra parte, se plantea la cuestión relativa al procedimiento a seguir en estos casos, ya que, por tratarse de actos jurídicos privados, no existe procedimiento sustantivo principal -como en la autorización- en el que se incorpore la EIA, tal como prevé el art. 1.2 del TRLEIAP no reformado. La obligada realización también en estos casos de las actuaciones integrantes de la EIA (art. 5.1 del TRLEIAP reformado) se complica en su necesaria conexión con el procedimiento principal aquí inexistente (art. 9.1 y 2 TRLEIAP). La reforma pretende resolver este problema, con referencia exclusiva a la Administración General del Estado, mediante varias reglas que tratan de sustituir el esquema autorizatorio en lo necesario, a partir de la presentación de la solicitud de autorización del proyecto con el correspondiente estudio de impacto ambiental. El régimen procedimental aplicable desde ese momento en el caso de la declaración responsable y comunicación sería el siguiente:

a) Se atribuye al órgano sustantivo la realización de los trámites información pública y de consulta (nuevo párrafo tercero del art. 9.1 TRLEIAP reformado). 
b) Se crea un trámite nuevo, sucedáneo de la solicitud de autorización, consistente en la presentación de una solicitud de declaración de impacto ambiental, que será objeto de información pública en vez de aquella [art. 9.2.a) TRLEIAP modificado]. Dado el momento en que se inserta y su conexión con el procedimiento relativo a la actividad, parece, pese al silencio de la norma, que incumbe presentarla al promotor. Es un trámite no incluido dentro de las actuaciones integrantes de la EIA (art. 5.1 modificado) e inexistente en el caso de la autorización, pues es el órgano sustantivo el que remite el expediente al órgano ambiental para que formule la declaración de impacto ambiental (art. 12.1 no reformado TRLEIAP), que puede exigir que se complete el estudio de impacto ambiental (art. 17, párrafo tercero, del Reglamento aprobado por Real Decreto 1131/1988). La razón de aquella solicitud parece estribar en permitir al órgano sustantivo la realización del procedimiento de forma conexa con las nuevas técnicas, pues la remisión del expediente al órgano ambiental en todo caso es la determinante del inicio de la fase 3 (art. 12.2, párrafo segundo, TRLEIAP, reformado).

c) No parece bien resuelta la adecuación relativa a la información sobre la decisión de autorización del proyecto, de obligada publicidad. El nuevo art. 15.3 del TRLEIAP alude tanto en su inicio (“decisiones") como al final (“adopción por el órgano sustantivo") a decisiones del órgano sustantivo, desconociendo que la declaración responsable y la comunicación se caracterizan por no precisar del consentimiento de la Administración, salvo utilización del veto o declaración de ineficacia en caso de incumplimiento de condiciones esenciales (art. 71 bis.4 Ley 30/1992). Por ello, lo normal en estos casos debiera ser la publicidad, en extracto, de la declaración responsable y de la comunicación una vez se produzca su eficacia.

Finalmente, se incorporan estas dos técnicas a otras modificaciones, de menor relieve y referidas también a la Administración General del Estado, en la misma posición que la autorización o aprobación.

Así pues, se ha irradiado el esquema procedimental previsto para las autorizaciones a los supuestos de declaración responsable y comunicación respecto de proyectos sujetos a EIA ${ }^{18}$, por lo que, teniendo en cuenta además la sanción de invalidez e ineficacia para

\footnotetext{
${ }^{18}$ Hasta el punto de que el art. 12.2 del TRLEIAP resulta contradictorio o incoherente, pues en su inciso inicial alude a los "aspectos relevantes relacionados con el procedimiento de autorización del proyecto y, en concreto, lo siguientes" y en su letra a) se refiere a proyectos en los que no es necesario la autorización, por estar sometidos a declaración responsable o comunicación, por lo que en ellos no hay procedimiento de autorización del proyecto.
} 
el caso de incumplimiento, parece discutible la opción elegida de posibilitar en estos casos tales técnicas de intervención posterior. La regulación comunitaria y el carácter preventivo y esencial -con especial densidad- de la EIA permiten entender justificado el mantenimiento en tales casos del régimen de autorización por concurrir su necesidad por una razón imperiosa de interés general basada en la protección del medio ambiente y la proporcionalidad.

\section{OTRAS MODIFICACIONES DE CARÁCTER BÁSICO}

El segundo bloque de reformas se refiere a otras modificaciones de carácter básico del TRLEIAP introducidas por la Ley 6/2010, que en la mayoría de los casos -salvo el art. 5.1 y la disposición final tercera- proceden de la tramitación parlamentaria. Son las siguientes:

a) Art. 5.1 TRLEIAP: consiste en un ajuste en la relación de las actuaciones que integran la EIA, ya que la declaración de impacto ambiental, antes prevista en el apartado 2, pasa a incorporarse como letra e) del apartado 1. Este reacomodo obedece a la posterior determinación de fases de actuaciones respecto de la Administración General del Estado (art. 5.2), para fijar plazos de desarrollo con la finalidad de una mayor eficacia.

b) Art. 5.3 TRLEIAP: "La evaluación de impacto ambiental comprenderá la totalidad del proyecto y no sólo las evaluaciones de impacto parciales de cada fase o parte del proyecto". Esta destacada reforma pretende impedir la quiebra del carácter global de la EIA mediante la fragmentación de proyectos $^{19}$, sin que el fraccionamiento impida la aplicación de los Anexos (Nota al final de los Anexos de la Directiva y del Anexo I del TRLEIAP). La reforma acoge la jurisprudencia comunitaria que alerta del riesgo del fraccionamiento de un proyecto de una larga distancia en tramos sucesivos de pequeña importancia para que tanto el proyecto considerado en su globalidad como los tramos surgidos de dicho fraccionamiento pudieran eludir lo dispuesto en la Directiva ${ }^{20}$; pues ésta contempla una apreciación global del impacto de los proyectos o de su modificación sobre el medio ambiente, sin que puedan considerarse únicamente los impactos directos de las obras proyectadas, sin tener en cuenta las repercusiones sobre

\footnotetext{
${ }^{19}$ RAZQUIN LIZARRAGA, J. A., La evaluación de impacto ambiental cit., pp. 165-168.

${ }^{20}$ Sentencia del TJCE de 19 de septiembre de 2004 (C-227/01, Comisión/España).
} 
el medio ambiente de la utilización y explotación de las construcciones resultantes de dichas obras ${ }^{21}$; así como la jurisprudencia interna que exige una consideración conjunta de los proyectos que vienen a integrar una instalación de carácter unitario ${ }^{22}$.

c) Arts. 6.3 y 16.1 TRLEIAP: se exige que el documento inicial del proyecto identifique a su autor o autores mediante nombre, apellidos, titulación y documento nacional de identidad" (art. 6.3). Su propósito -explicitado en las enmiendas- es permitir la exigencia de responsabilidades por la redacción de los proyectos, propiciando una mayor calidad de los trabajos, que a su vez genere ahorro de tiempo y recursos para el promotor y la propia Administración. Sin embargo, esta previsión básica difiere de algún precedente en la legislación autonómica y de lo señalado en el propio texto legal para el ámbito estatal (art. 7.4 TRLEIAP), ya que éstos se refieren a los estudios de impacto ambiental, mientras que el precepto reformado alude al documento inicial del proyecto (no al proyecto ni al estudio de impacto ambiental).

En similar línea, se modifica el art. 16.1 del TRLEIAP para incorporar un párrafo final a cuyo tenor el documento ambiental identificará a su autor o autores mediante nombre, apellidos, titulación y documento nacional de identidad; por lo que aquí concuerda con las aludidas previsiones autonómicas y para el ámbito estatal.

d) Art. 12.2, párrafo primero, TRLEIAP: los plazos procedimentales eran una cuestión remitida lógicamente a su determinación por la legislación autonómica, fijándose únicamente los referidos a la Administración General del Estado. Este criterio se quiebra en la reforma del art. 12.2, párrafo primero, del TRLEIAP, ya que, en sede parlamentaria, se añadió un inciso final: "sin que éstos puedan tener un techo máximo para la realización de la fase 2 inferior a 18 meses". Con ello no sólo se fija por el legislador estatal un plazo para la tramitación autonómica, sino que se hace de forma asistemática: las fases de las actuaciones están previstas en el art. 5.2 solo para la Administración General del Estado, tales actuaciones se contemplan para las Comunidades Autónomas en el art. 10.1 -no reformado- que remite a la fijación de

\footnotetext{
${ }^{21}$ Sentencia del TJCE de 25 de junio de 2008 (C-142/07, Ecologistas en Acción-CODA/Ayuntamiento de Madrid). Asimismo, Sentencias del TJCE de 21 de septiembre de 1999 (C-392/96, Comisión/Irlanda), de 28 de febrero de 2008 (C-2/07, Abraham y otros) y de 10 de diciembre de 2009 (C-205/08, Umweltanwalt von Kärnten).

${ }^{22}$ STS de 20 de abril de 2006 (RJ 2006, 3140) y, sobre todo, Sentencia de la Sala de lo ContenciosoAdministrativo del TSJ de Castilla-León núm. 1448/2009, de 10 de junio de 2009, que confirma la anulación por el Juzgado de la autorización para la instalación de un parque eólico. Véase SANZ RUBIALES, I., "Los efectos ambientales acumulativos de los parques eólicos. Su evaluación", Revista Jurídica de Castilla y León, núm. 21, 2010, pp. 185-216.
} 
plazos por aquellas sin límite alguno y el art. 12.2 se refiere a la fase 3. Por tanto, no se justifica su carácter básico ni el inciso añadido guarda coherencia con el resto del texto legal.

e) Disposición adicional primera, párrafo segundo, TRLEIAP: en este precepto, sobre los proyectos excluidos de EIA, se añade un nuevo párrafo autorizando al Consejo de Ministros o al órgano correspondiente de la Comunidad Autónoma competente, con arreglo a la disposición adicional segunda, para excluir caso por caso de la EIA los proyectos de centros penitenciarios por razones de seguridad ${ }^{23}$. Esta modificación obedece a los conflictos planteados con ocasión de la aplicación de la exclusión a los centros penitenciarios $^{24}$ y no ha sido pacífica, pues prevista en el anteproyecto, decayó en el proyecto y fue añadida en el trámite parlamentario, con la oposición por razón del cumplimiento del derecho comunitario por el Grupo Socialista ${ }^{25}$, incorporándose finalmente algunos matices de redacción. El nuevo párrafo carece de carácter automático o general, refiriéndose a los casos concretos en que corresponda tal exclusión por motivos de seguridad; y no puede ser una dispensa, pues, en virtud de la remisión a la disposición adicional segunda, se trata de un modo alternativo o sustitutivo de evaluación ${ }^{26}$.

f) Disposición final tercera TRLEIAP: se introduce esta nueva disposición para expresar la incorporación por dicha norma del Derecho de la Unión Europea, en concreto de la Directiva 85/337/CEE.

\footnotetext{
${ }^{23}$ El Consejo de Estado en su dictamen de 25 de junio de 2009 (exp. 981/2009) sobre el anteproyecto de ley de modificación del TRLEIAP, indicó que "una exclusión tan categórica de todos los centros penitenciarios sin atención a casos especiales parece pues muy dudosa desde la perspectiva del Derecho comunitario y podría dar lugar a múltiples problemas posteriores mayores que los que se trata de evitar", pudiendo utilizarse otras fórmulas previstas en la Directiva para excluir en su caso estos supuestos o, lo que es quizá más lógico, limitar la información acerca de los mismos en el proceso de evaluación.

${ }^{24}$ Los AATS (Sala de lo Contencioso-Administrativo, Sección 5a) de 16 abril 2009 (JUR 2009\231165) y de 15 septiembre 2009 (JUR 2009\423777, con un voto particular que no aparece publicado) rechazan la peticiones del Ayuntamiento afectado y una asociación de suspensión cautelar de la ejecutividad del Acuerdo del Consejo de Ministros por el que se declara excluido el trámite de impacto ambiental el proyecto de construcción de un nuevo centro penitenciario en Pamplona formulada; y el ATS (Sala de lo Contencioso-Administrativo, Sección $5^{\text {a }}$ ) de 13 julio 2009 (JUR 2009\350264) deniega la suspensión del acuerdo del Consejo de Ministros excluyendo de evaluación de impacto ambiental un proyecto de construcción de un centro penitenciario en Álava (con un Voto Particular que no aparece publicado).

${ }^{25}$ Enmienda núm. 13 del Grupo Parlamentario Socialista en el Senado proponiendo la supresión.

${ }^{26}$ STC 13/1998, en cuanto a la exclusión de la evaluación de impacto ambiental de los proyectos aprobados específicamente por una Ley del Estado (FJ 12) y a la constitucionalidad competencial de la previsión de proyectos exceptuables (FJ 13). Asimismo, SSTJCE de 16 de septiembre de 1999 (C-435/97, WWF) y de 19 de septiembre de 2000 (C-287/98, Linster y otros).
} 


\section{MODIFICACIONES REFERIDAS A LA ADMINISTRACIÓN GENERAL DEL ESTADO.}

El tercer bloque de modificaciones se refiere únicamente a la Administración General del Estado y responde a los dos objetivos señalados en la exposición de motivos de la Ley 6/2010, así como a la futura reglamentación del procedimiento de evaluación de proyectos que puedan afectar de forma apreciable a espacios protegidos de la Red Natura 2000.

\section{Medidas para la eficacia y agilidad: plazos}

Desde la primera perspectiva, se modifica el art. 5.2 del TRLEIAP agrupando las actuaciones de la EIA en tres fases: la fase 1, determinación del alcance del estudio de impacto ambiental, comprende las actuaciones de las letras a) (solicitud del promotor ante el órgano sustantivo de sometimiento del proyecto a EIA) y b) (determinación del alcance del estudio de impacto ambiental por el órgano ambiental) del art. 5.1; la fase 2, estudio de impacto ambiental, información pública y consultas, comprende tales actuaciones indicadas en las letras c) y d) del art. 5.1; y la fase 3, declaración de impacto ambiental, comprende dicha actuación prevista en la letra e) del art. 5.1.

La fase 1 comienza con la presentación ante el órgano sustantivo de la solicitud de sometimiento del proyecto a EIA y la documentación correspondiente, que, una vez comprobada su conformidad formal por el órgano sustantivo, se remitirá al órgano ambiental (art. 6.2 TRLEIAP reformado) ${ }^{27}$.

La fase 2 se inicia con la notificación efectuada por el órgano ambiental sobre el alcance y el nivel de detalle del estudio de impacto ambiental (art. 7.3 TRLEIAP reformado) y el plazo para la realización del conjunto de actuaciones que comprende (estudio de impacto ambiental, información pública y consultas) no podrá exceder de 18 meses a contar desde la recepción de aquella notificación por el promotor (párrafo primero del art. 10.2 TRLEIAP reformado), lo que supone una reducción del actual plazo de 2 años.

\footnotetext{
${ }^{27}$ Se mantiene el plazo de 3 meses para trasladar al promotor la amplitud y el nivel de detalle del estudio de impacto ambiental, así como las contestaciones recibidas a las consultas efectuadas, a computar desde la recepción por el órgano ambiental de la solicitud y de la documentación a que se refiere el art. 6 (art. 8.3 TRLEIAP no modificado).
} 
El efecto de su incumplimiento -por no haber recibido el expediente el órgano ambiental- es diferente según quien sea el responsable: si obedece a causas imputables únicamente al promotor se archivará el expediente y, en cambio, cuando las causas fuesen imputables únicamente al órgano sustantivo o conjuntamente a éste y al promotor, el órgano ambiental decidirá motivadamente, de oficio o a petición del órgano sustantivo, el archivo del expediente o la ampliación del plazo hasta un máximo de 9 meses (párrafos segundo y tercero del art. 10.2 TRLEIAP reformado).

La fase 3 se inicia con la remisión del expediente al órgano ambiental, que deberá producirse dentro del plazo señalado en el art. 10.2, debiendo éste formular la declaración de impacto ambiental en el plazo máximo de 3 meses desde la recepción del expediente completo, que será notificada al promotor en el plazo de 15 días desde su recepción sin perjuicio de su publicación en la página web del órgano ambiental (párrafos segundo y tercero del art. 12.2 TRLEIAP modificado).

El acto sobre la realización o no del proyecto se remitirá en el plazo de 15 días desde su adopción por el órgano sustantivo para su publicación en extracto en el Boletín Oficial del Estado (art. 15.3 TRLEIAP reformado).

Asimismo, se fija la caducidad de las declaraciones de impacto ambiental anteriores a la entrada en vigor de la disposición final primera de la Ley 9/2006, que mantienen su validez durante un plazo de 3 años desde el 26 de marzo de 2010 -fecha de entrada en vigor de la Ley 6/2010-, sin perjuicio de que antes de la ejecución de los proyectos deberá solicitarse informe del órgano ambiental sobre si se han producido cambios sustanciales en los elementos esenciales que sirvieron de base para realizar la EIA, que se entiende favorable a la vigencia de la declaración, si no se emite y notifica el informe en el plazo de 60 días; una vez transcurrido el plazo de pervivencia de 3 años entra en juego el régimen de caducidad de la declaración de impacto ambiental fijado en el art. 14 del TRLEIAP (disposición transitoria segunda de la Ley 6/2010).

La agrupación de las actuaciones en fases y la determinación de plazos para su realización merecen algunas observaciones críticas: en primer lugar, tal agrupación no parece justificada, necesaria ni coherente, ya que la fase 1 realmente sólo incluye la actuación de la determinación que se abre con la presentación de la solicitud de sometimiento a EIA por el promotor, la fase 2 recoge actuaciones heterogéneas, una responsabilidad del promotor y otras del órgano sustantivo competente, con los 
consiguientes problemas respecto de los efectos del incumplimiento de los plazos, y la fase 3 incluye una única actuación. En segundo lugar, se fijan dos momentos distintos para el inicio del cómputo del plazo en la fase 3, pues ésta se inicia con la remisión del expediente al órgano ambiental (párrafo segundo del art. 12.2 TRLEIAP modificado) y, en cambio, el plazo máximo para realizar la actuación de esta fase comienza desde la recepción del expediente completo por el órgano ambiental (párrafo tercero del art. 12.2 TRLEIAP modificado). En tercer lugar, tampoco son homogéneas las expresiones entre el final de la fase 2 y el comienzo de la fase 3 , ya que aquella termina con la recepción por el órgano ambiental del estudio de impacto ambiental, el documento técnico del proyecto y el resultado de la información pública (párrafo segundo del art. 10.2 TRLEIAP modificado), mientras que el inicio de ésta -tanto por remisión como por recepción- se refiere al expediente -como también hace el art. 12.1 no reformado- o mejor al expediente completo (párrafos segundo y tercero del art. 12.2 TRLEIAP modificado). Y, en cuarto lugar, la solución arbitrada con la reforma del art. 10.2 para la Administración general del Estado difiere de la prevista con carácter básico en el apartado 1 del mismo precepto legal, donde imperativamente se indica para el caso de incumplimiento que "se procederá a archivar el expediente".

Finalmente, en los proyectos de la competencia estatal se exige que tanto el estudio de impacto ambiental como el documento ambiental identifiquen a su autor o autores mediante nombre, apellidos, titulación y documento nacional de identidad (arts. 7.4 añadido y 16.2 , párrafo primero, reformado TRLEIAP).

\section{Reformas de incorporación formal de las técnicas de control posterior}

A las reformas de adaptación a la transposición de la Directiva de servicios se aludido más atrás, consistiendo, en lo que al ámbito estatal se refiere, en la inclusión de las dos técnicas de intervención posterior en determinados preceptos junto a la ya prevista autorización o aprobación [arts. 6.2, 7.3 y 4, 9.1 párrafo tercero, 9.2 letras a) y c), 10.2, 12.2 párrafo segundo y 16.2 del TRLEIAP]. Además, se incorpora un precepto de adecuación normativa, que constituye una cláusula de cierre que cubre supuestos no recogidos, de modo que en las referencias del texto refundido al órgano de la Administración General del Estado competente para la aprobación o autorización del proyecto, se entenderá por extensión incluido el competente para controlar la actividad a 
través de la comunicación o declaración responsable (nueva disposición adicional sexta TRLEIAP).

\section{La evaluación de proyectos estatales que puedan afectar de forma apreciable a espacios de la Red Natura 2000}

La Directiva 92/43/CE del Consejo, de 21 de mayo de 1992, relativa a la conservación de los hábitats naturales y de la fauna y flora silvestres, prevé la evaluación de las repercusiones de cualquier plan o proyecto que, sin tener relación directa con la gestión del lugar o sin ser necesario para la misma, pueda afectar de forma apreciable a una zona de especial protección, un espacio protegido de la Red Natura 2000 (apartados 3 y 4 del art. 6$)^{28}$.

En el ámbito estatal, la Directiva 92/43/CE fue adaptada inicialmente por el Real Decreto 1997/1995, de 7 de diciembre, por el que se establecen medidas para contribuir a garantizar la biodiversidad mediante la conservación de los hábitats naturales y de la fauna y flora silvestres, que también alude a la evaluación de las repercusiones de los planes y proyectos que afecten a tales lugares (apartados 3 y 4 del art. 6); evaluación actualmente establecida en los apartados 4 a 9 del art. 45 de la Ley 42/2007, de 13 de diciembre, de Patrimonio Natural y de la Biodiversidad. La Ley 62/2003, de 30 de diciembre, añadió una nueva disposición adicional cuarta (evaluación ambiental de planes y proyectos estatales previstos en el art. 6 del Real Decreto 1997/1995) al Real Decreto Legislativo 1302/1986 con la finalidad de coordinar ambas evaluaciones desde la perspectiva de la EIA, que hoy se recoge actualizada en la disposición adicional cuarta del TRLEIAP ${ }^{29}$.

\footnotetext{
${ }^{28}$ Sobre este precepto existen dos guías o documentos de la Comisión Europea: Assessment of plans and projects significantly affecting Natura 2000 sites. Methodological guidance on the provisions of Article 6(3) and (4) of the Habitats Directive 92/43/EEC, Noviembre 2001; y Documento orientativo sobre el apartado 4 del artículo 6 de la «Directiva sobre hábitats» 92/43/CEE (clarificación de los conceptos de soluciones alternativas, razones imperiosas de interés público de primer orden, medidas compensatorias, coherencia global y Dictamen de la Comisión), Enero de 2007.

${ }^{29}$ Su apartado 1 dice así: "La evaluación de los proyectos que, sin tener relación directa con la gestión del lugar de que se trate de la Red Natura 2000 o sin ser necesario para la misma, pueda afectar de forma apreciable a los citados lugares ya sea individualmente o en combinación con otros planes o proyectos, se someterá a una adecuada evaluación de sus repercusiones en el lugar teniendo en cuenta los objetivos de conservación de dicho lugar, conforme a lo dispuesto en la Ley 42/2007, de 13 de diciembre, de patrimonio natural y de la biodiversidad, sin perjuicio de lo establecido en la presente ley".
} 
Según los arts. 6.3 y 4 de la Directiva $92 / 43$ y 45.4 a 9 de la Ley 42/2007, la evaluación de planes y proyectos que puedan afectar de forma apreciable a lugares de la Red Natura 2000 se configura, en síntesis, del modo siguiente ${ }^{30}$ : se refiere tanto a proyectos como a planes y programas, con un criterio amplio y sin umbrales; la Directiva 92/43 no diseña un método específico o unos concretos requisitos procedimentales para desarrollar la evaluación, por lo que los Estados miembros son, en principio, libres para establecer el procedimiento evaluatorio que deseen sin sujeción necesariamente a las exigencias establecidas en la Directiva EIA ni en la Directiva 2001/42/CE, pero ha de tratarse de una "adecuada evaluación" teniendo en cuenta los objetivos de conservación del lugar; este proceso de evaluación adecuada no es un mero acto administrativo formal, sino que debe proporcionar un análisis en profundidad acorde con los objetivos de conservación establecidos para el lugar de que se trate, en particular en lo relativo a la protección de los hábitats naturales y de las especies prioritarios ${ }^{31}$, por lo que esta evaluación implica que es preciso identificar, a la luz de los mejores conocimientos científicos en la materia, todos los aspectos del plan o del proyecto que, por sí solos o en combinación con otros planes o proyectos, puedan afectar a dichos objetivos ${ }^{32}$; tiene aquí especial trascendencia el principio de cautela o precaución, por lo que, como regla, la autorización sólo puede concederse cuando se tenga la certeza de que la actividad no producirá efectos perjudiciales para la integridad del lugar ${ }^{33}$; si bien se admiten excepciones, pues si, a pesar de las conclusiones negativas de la evaluación y a falta de soluciones alternativas, debiera realizarse un plan, programa o proyecto por razones imperiosas de interés público de primer orden, incluidas razones de índole social o económica, las Administraciones Públicas competentes tomarán cuantas medidas

\footnotetext{
${ }^{30}$ GARCÍA URETA, A., Derecho Europeo de la Biodiversidad: Aves silvestres, hábitats y especies de flora y fauna, Iustel y Gómez-Acebo\&Pombo, Madrid, 2010, pp. 528-589.

${ }^{31}$ Sentencia del TJCE de de 14 de abril de 2005 (C-441/03, Comisión/Países Bajos, ap. 22).

32 Sentencia del TJCE de 7 de septiembre de 2004 (C-127/02, Waddenvereniging y Vogelbeschermingsvereniging, ap. 54).

${ }^{33}$ Sentencias del TJCE de 6 de abril de 2000 (C-256/98, Comisión/Francia); de 20 de marzo de 2003 (C143/02, Comisión/Italia); 7 de septiembre de 2004 (C-127/02, Waddenvereniging y Vogelbeschermingsvereniging); de 20 de octubre de 2005 (C-6/04, Comisión/Reino Unido); de 10 de enero de 2006 (C-98/03, Comisión/Alemania); de 26 de octubre de 2006 (C-239/04, Comisión/Portugal, "Castro Verde"); de 13 de septiembre de 2007 (C-418/04, Comisión/Irlanda); de 18 de septiembre de 2007 (C-186/07, Comisión/España); de 20 de septiembre de 2007 (C-304/05, Comisión/Italia); y de 4 de octubre de 2007 (C-179/06, Comisión/Italia). Por todos, GARCÍA URETA, A., Protección de hábitats y de especies de flora y fauna en Derecho Comunitario Europeo. Directivas 79/409 y 92/43, IVAP, Oñati, 1997, pp. 278-300; y del mismo autor, Derecho Europeo de la Biodiversidad cit., pp. 528-589; así como, GARCÍA URETA, A., y CUBERO MARCOS, J. I., "Directiva de hábitats: principio de precaución y evaluación de planes y proyectos", RVAP, núm. 70, 2004, pp. 361-382.
} 
compensatorias sean necesarias para garantizar que la coherencia global de Natura 2000 quede protegida, que se adoptarán en su caso durante el procedimiento de EAE o de EIA, debiendo informarse a la Comisión Europea.

Así pues, esta evaluación, pese a su proximidad con la EIA, es singular y con diferencias de contenido de determinadas prescripciones de ésta (STJCE de 23 de marzo de 2006, C-209/04, Comisión/Austria). Como ha señalado el TJCE, “estas dos Directivas (Directivas 85/337 y 2001/42) contienen disposiciones relativas al procedimiento de deliberación sin vincular a los Estados miembros en cuanto a la decisión y sólo se refieren a determinados proyectos y planes. En cambio, a tenor del artículo 6, apartado 3, segunda frase, de la Directiva sobre los hábitats, un plan o un proyecto sólo puede autorizarse cuando las autoridades nacionales competentes se hayan asegurado de que no causa perjuicio a la integridad del lugar. Por lo tanto, las evaluaciones en virtud de la Directiva 85/337 o de la Directiva 2001/42 no pueden sustituir al procedimiento previsto en el artículo 6, apartados 3 y 4, de la Directiva sobre los hábitats" (STJCE de 13 de septiembre de 2007, C-418/04, Comisión/Irlanda, ap. 231).

De ahí que, por tratarse de técnicas y procedimientos distintos ${ }^{34}$, el procedimiento de EIA no suple necesariamente el régimen y la evaluación previstos en los arts. 6 de la Directiva 92/43 y 45 de la Ley 42/2007, cuyas exigencias deben ser cumplidas ${ }^{35}$. La Comisión Europea ha apuntado que los vínculos fijados por algunos Estados miembros entre la Directiva EIA y las Directivas ZEPAS y Hábitats no siempre permiten una evaluación ajustada a las exigencias de estas últimas ${ }^{36}$.

\footnotetext{
${ }^{34}$ La evaluación prevista en la Directiva 92/43/CEE no es coincidente con la EIA, por lo que los proyectos previstos situados en esas áreas no tienen necesariamente que ser sujetos al procedimiento de EIA propiamente dicho, según se indica en el considerando 10 del preámbulo de la Directiva 97/11/CE.

${ }^{35}$ Véanse STS de 29 de noviembre de 2006 (RJ 2007, 8317) y sentencias de la Sala de lo ContenciosoAdministrativo del TSJ de Madrid núm. 169/2008, de 14 de febrero de 2008 (JUR 2008\130624) y núm. 946/2008, de 1 de julio (RJCA 2008, 398).

${ }^{36}$ El Informe de la Comisión al Consejo, al Parlamento Europeo, al Comité Económico y Social Europeo y al Comité de las Regiones sobre la aplicación y eficacia de la Directiva EIA (Directiva 85/337/CEE del Consejo, modificada por las Directivas 97/11/CE y 2003/35/CE) [COM(2009) 378 final, Bruselas, 23.7.2009], apartado "EIA y biodiversidad", indica: "Los Estados miembros han establecido vínculos formales e informales entre la Directiva EIA y las Directivas de Hábitats y de Aves (en particular con el artículo 6, apartados 3 y 4 de la primera). Aunque no se ha notificado ningún problema grave, la experiencia de la Comisión pone de manifiesto que los requisitos del artículo 6, apartados 3 y 4 , no se tienen debidamente en cuenta en los procedimientos de EIA. Además, esos procedimientos se centran en el impacto sobre espacios de la red Natura 2000, pero suelen desatenderse las disposiciones sobre conservación de especies", apuntado que "las consideraciones en materia de biodiversidad podrían reflejarse de forma expresa en el texto de la Directiva EIA. También podría establecerse un
} 
A esta preocupación responde la adición de un párrafo segundo al apartado 1 de la disposición final segunda del TRLEIAP (por art. único.14 Ley 6/2010), autorizando al Gobierno para regular mediante Real Decreto los requisitos adicionales y la metodología que deba utilizarse en la evaluación de impacto ambiental de los proyectos de competencia de la Administración General del Estado que puedan afectar de forma apreciable a los espacios protegidos de la Red Natura 2000, de acuerdo con lo establecido en el TRLEIAP y en la Ley $42 / 2007^{37}$. Se trata, en fin, de una mera

procedimiento de evaluación único para los proyectos a los que se aplican la Directiva EIA y el artículo 6 , apartados 3 y 4, de la Directiva de Hábitats".

37 Se acoge la recomendación del Consejo de Estado en su dictamen de 25 de junio de 2009 (exp. 981/2009) sobre el anteproyecto de ley de modificación del TRLEIAP, indicando:

"Gran parte de las evaluaciones de impacto son de preceptiva realización debido a que el proyecto se realiza o afecta a un lugar de la Red Natura 2000 (que supone un alto porcentaje del territorio nacional) y tanto la Directiva Hábitats como ahora la Ley 42/2007, de 13 de diciembre, del Patrimonio Natural y de la Biodiversidad, exigen un tipo concreto de evaluación de impacto que no está todavía regulado propiamente en nuestro Derecho ya que la solución adoptada hasta la fecha en nuestras leyes no consiste en adaptar la evaluación de impacto a estas exigencias (que habría sido lo lógico) sino que, desde el año 2000 en que se aborda el problema, lo que se hace es adaptar la evaluación especial de estos lugares a las exigencias de la evaluación de impacto ordinaria o general [ya que la ley se limita a exigir siempre en esos casos que se haga una evaluación de impacto "ordinaria" cuando lo que habría que hacer, en cualquier caso, es una evaluación especial]. Así, el propio artículo 45.4 de la Ley 42/2007, parafraseando el tenor literal de la Directiva, señala que "cualquier plan, programa o proyecto que, sin tener relación directa con la gestión del lugar o sin ser necesario para la misma, pueda afectar de forma apreciable a los citados lugares, ya sea individualmente o en combinación con otros planes o proyectos, se someterá a una adecuada evaluación de sus repercusiones en el lugar,...". La "adecuación" depende de metodologías específicas que tengan en cuenta la afección a los concretos hábitats y especies que han dado lugar a la inclusión del lugar en la Red Natura 2000 y que se encuentran en fichas y documentos que muchas veces no son públicos. Ello hace que muchos de los estudios, o no se hagan específicamente sobre esos extremos, o se hagan muy defectuosamente, con los consiguientes múltiples conflictos de los promotores (y autoridades sustantivas) con los órganos ambientales llamados a hacer la declaración de impacto o, posteriormente, con la Comisión Europea.

Las modificaciones llevadas a cabo en 2003 y 2006 en el Real Decreto 1995/1997 que, antes de la promulgación de la Ley 42/2007 era (y sigue siendo en parte) la norma de transposición de la Directiva Hábitats, se ha demostrado insuficiente al respecto al solucionar sólo uno de los problemas (la inclusión de las medidas de compensación en la declaración de impacto).

El expediente ha puesto de relieve la urgente necesidad de solucionar este problema, lo que no pudo acometerse en la elaboración del Real Decreto Legislativo 1/2008 al ser éste un texto refundido que no podía modificar la legislación entonces vigente.

(...)

Para solucionar este problema, dada la trascendencia que tiene darle pronta solución y sin tener que recurrir dentro de muy poco a una nueva reforma del Real Decreto Legislativo $1 / 2008$, entiende el Consejo de Estado que debería añadirse un mandato al Gobierno, en una nueva disposición adicional a añadir al anteproyecto, para que en un plazo relativamente corto elabore un proyecto de real decreto que, tomando en cuenta la regulación actual de la evaluación de impacto ambiental y las exigencias del artículo 45.4 de la Ley 42/2007 y del artículo 6.3 de la Directiva Hábitats, elabore un reglamento que 
autorización para una futura reglamentación del procedimiento de esta evaluación, referida al ámbito estatal.

\section{CONCLUSIÓN}

La EIA es una fundamental técnica para prevenir y evitar el deterioro ambiental -como indicada la exposición de motivos de la Ley 6/2010-, por lo que es vital garantizar la seguridad jurídica en su regulación legal, tanto en términos de estabilidad como de claridad y previsibilidad.

Desde este examen rápido, no parece que ese objetivo se cumpla cabalmente con las reformas del TRLEIAP por la Ley 6/2010, sin perjuicio de la conveniencia de algunas de ellas. Es discutible la traslación de las técnicas de control posterior a las actividades sujetas a EIA, así como el procedimiento diseñado, que no deja de ser un remedo del previsto para los regímenes de autorización, con la creación de una novedosa solicitud de declaración de impacto ambiental. La regulación de los plazos para realizar las fases de EIA en cuanto a la Administración General del Estado resulta confusa y problemática, pues no parece necesaria la agrupación en fases, ni se delimita claramente la imputación de las responsabilidades correspondientes derivadas de su incumplimiento ni son homogéneos los días de inicio y fin. Asimismo, se trata de una reforma parcial y fragmentaria que provoca desajustes sistemáticos en el texto resultante del TRLEIAP.

Finalmente, la evolución continuará con sucesivas reformas normativas. Además de la prevista reglamentación del procedimiento de evaluación de la Directiva hábitats para los proyectos de la competencia estatal, falta la transposición de la última modificación de la Directiva comunitaria actualmente en curso $^{38}$, sin olvidar las adaptaciones y reformas de la legislación autonómica.

regule los requisitos adicionales y la metodología que debe utilizarse en la realización de las evaluaciones de las repercusiones de impacto ambiental de proyectos que puedan afectar de forma apreciable a los lugares de la Red Natura 2000".

${ }^{38}$ El proyecto de Ley de almacenamiento geológico de dióxido de carbono recientemente remitido por el Gobierno a las Cortes (BOCG, Congreso de los Diputados, Serie A, Núm. 78-1, de 16 de abril de 2010) transpone la Directiva 2009/31/CE modificando el TRLEIAP (disposición final segunda). 


\section{BIBLIOGRAFÍA}

GARCÍA URETA, A., Protección de hábitats y de especies de flora y fauna en Derecho Comunitario Europeo. Directivas 79/409 y 92/43, IVAP, Oñati, 1997.

— "La evaluación de impacto ambiental (EIA)", Lasagabaster Herrarte, I., García Ureta, A., Lazcano Brotons, I., Derecho Ambiental. Parte general, $2^{\mathrm{a}}$ ed., Lete e IVAP, Pamplona, 2004.

- Derecho Europeo de la Biodiversidad: Aves silvestres, hábitats y especies de flora y fauna, Iustel y Gómez-Acebo\&Pombo, Madrid, 2010.

GARCÍA URETA, A., y CUBERO MARCOS, J. I., "Directiva de hábitats: principio de precaución y evaluación de planes y proyectos", RVAP, núm. 70, 2004.

LÓPEZ RAMÓN, F., "Evaluación de impacto ambiental de proyectos del Estado", RAP, núm. 160, 2003.

QUINTANA LÓPEZ, T., "La evaluación de impacto ambiental”, en Quintana López, T., Comentario a la legislación de evaluación de impacto ambiental, Civitas, Madrid, 2002.

RAZQUIN LIZARRAGA, J. A., La evaluación de impacto ambiental, Ed. Aranzadi, Elcano (Navarra), 2000.

— "De la intervención administrativa previa al control a posteriori: la reforma del procedimiento administrativo común a consecuencia de la directiva de servicios", Revista Aranzadi Doctrinal, núm. 2/2010 (BIB 2010\285).

ROSA MORENO, J., "El ámbito de aplicación: los proyectos de obras, instalaciones y actividades sometidos a evaluación de impacto ambiental”, en Quintana López, T., Comentario a la legislación de evaluación de impacto ambiental, Civitas, Madrid, 2002.

SANZ RUBIALES, I., "Los efectos ambientales acumulativos de los parques eólicos. Su evaluación”, Revista Jurídica de Castilla y León, núm. 21, 2010. 